\title{
STRUCTURE AND PROPERTIES OF METAL DEPOSITED BY FLUX-CORED WIRE WITH CHARGE OF USED METAL-ABRASIVE WASTES
}

\author{
I.P. LENTYUGOV and I.A. RYABTSEV \\ E.O. Paton Electric Welding Institute, NASU \\ 11 Bozhenko Str., 03680, Kiev, Ukraine. E-mail: office@paton.kiev.ua
}

\begin{abstract}
The technology of recycling the grinding wastes of metal cutting tool was developed using electroslag remelting, allowing producing a master alloy of the certain chemical composition. The structure and wear resistance of metal of the similar chemical composition deposited using two pilot flux-cored wires was investigated. A charge of one of the wires was prepared of the master alloy produced after wastes recycling, a charge of the second one was prepared of the appropriate ferroalloys. The investigations showed that the metal deposited using both flux-cored wires had similar structures and approximately the same wear resistance. It was established that the master alloy produced by utilization of grinding wastes production can be successfully used as a charge in surfacing flux-cored wires. 4 Ref., 3 Tables, 3 Figures.
\end{abstract}

Keywords: metal-abrasive wastes, wastes recycling, flux-cored wires, surfacing materials, structure of deposited metal, wear resistance

Recycling of wastes, formed during abrasive machining of metal cutting tool or during high-speed grinding of ingots of high alloyed steels, is one of the challenging trends in the modern industrial production. These wastes are composed of oxidized metallic microchips mixed with abrasive particles and remnants of cutting fluid [1,2]. In addition, metal microchips contain the important alloying elements like chromium, tungsten, vanadium, molybdenum, etc. and their recycling and utilization represent interest not only from the ecological point of view. In particular, the recycling products of such wastes may be used as a charge in surfacing flux-cored wires [3].

At the E.O. Paton Electric Welding Institute the technology of recycling wastes from grinding of metal cutting tool was developed using electroslag remelting [3]. To remove the cutting fluid the calcination of metal abrasive wastes at the temperature of $200-400{ }^{\circ} \mathrm{C}$ is provided. In the process of calcination the wastes may be pelletized, therefore after calcination it is necessary to perform crushing of the formed lumps. The subsequent magnetic separation allows sorting out the metallic component of wastes.
Electroslag remelting of metallic component of wastes was performed in a copper mould using non-consumable graphite electrode. As a result of remelting the ingots of master alloy of a certain chemical composition were produced. At practicing the technology it was established that to provide stability of electroslag remelting process and the maximum output of quality master alloy the specific power should be at least $100 \mathrm{~W} / \mathrm{cm}^{2}$, and the feed rate of slime should be in the range of $2-3 \mathrm{~kg} / \mathrm{min}$.

Table 1 shows chemical composition of wastes at every stage of their recycling.

A high concentration of silicon in wastes is explained by the fact that silicon carbide penetrates them from abrasive discs. Preliminary magnetic separation of wastes can significantly reduce the silicon content. After electroslag remelting the content of silicon in master alloy is reduced to minimum. It is known that silicon carbide can recover oxides of a majority of other metals included into the composition of wastes, as a result of which silicon dioxide is formed, which is easily removed into slag during electroslag remelting.

Conducted were the comparative investigations of microstructure and tribological properties of metal, deposited using two flux-cored wires: in a charge of one of the wires a pilot

Table 1. Chemical composition of metal-abrasive wastes and master alloy produced of them, wt. \%

\begin{tabular}{||l|c|c|c|c|c|c|c|c||}
\hline \multicolumn{1}{|c|}{ Material } & $\mathrm{C}$ & $\mathrm{Si}$ & $\mathrm{Cr}$ & $\mathrm{Mo}$ & $\mathrm{V}$ & $\mathrm{W}$ & $\mathrm{Co}$ & $\mathrm{S}$ \\
\hline Metal-abrasive wastes & 1.8 & 15.60 & 1.4 & 0.8 & 0.85 & 5.89 & 0.32 & 0.039 \\
\hline Wastes after separation & 1.7 & 8 & 3.2 & 1.2 & 1 & 8 & 0.30 & 0.034 \\
\hline Master alloy & 4.9 & 0.23 & 2.7 & 2.6 & 0.63 & 9.88 & 0.20 & 0.080 \\
\hline
\end{tabular}


INTERNATIONAL CONFERENCE «SURFACING»

Table 2. Chemical composition of metal deposited using pilot flux-cored wires, wt.\%

\begin{tabular}{|c|c|c|c|c|c|c|c|c|c|}
\hline Flux-cored wire & $\mathrm{C}$ & $\mathrm{Si}$ & $\mathrm{Cr}$ & Mo & V & W & Co & $\mathrm{S}$ & Hardness \\
\hline PP-Op-01 & 1.68 & 0.50 & 1.52 & 0.85 & 0.2 & 3.0 & 0.13 & 0.012 & $50-52$ \\
\hline PP-Op-02 & 1.80 & 0.67 & 1.75 & 1.07 & 0.3 & 3.2 & Traces & 0.015 & $50-53$ \\
\hline
\end{tabular}

master alloy was used produced of metal-abrasive wastes; a charge of the second wire consisted of the appropriate ferroalloys. It was assumed that chemical composition and hardness of metal, deposited using both types of flux-cored wires, should be similar enough.

To perform this task a master alloy was melted of metal-abrasive wastes formed during grinding of tools of steel R6M5, according to the technology described above (for its chemical composition see Table 1).

The produced master alloy was crushed, refined and its powder was used as a charge in the pilot flux-cored wire with symbolic name PPOp-1. Using this wire under flux AN-26 the specimens were deposited and chemical analysis of the deposited metal was carried out (Table 2). According to the results of chemical analysis the second pilot flux-cored wire was manufactured, the charge of which was prepared of ferroalloys (PP-Op-2). The chemical composition of metal deposited using this wire under flux AN-26 is also given in Table 2 .

The specimens for investigation of microstructure were cut out from semi-products (steel St3), deposited in four layers using pilot flux-cored wires $\mathrm{PP}-\mathrm{Op}-1$ and $\mathrm{PP}-2-\mathrm{Op}-2$. The structure of deposited and base metal was revealed by chemical etching in $4 \%$ alcohol solution of nitric acid $\left(\mathrm{HNO}_{3}\right)$.

The investigations were carried out in the microscopes «Neophot-32» and «Polyvar». Microhardness of metal was measured on the LECO microdurometer M-400 at the loading of $100 \mathrm{~g}$. The investigations were conducted in accordance with GOST 5639-82 «Steels and alloys. Methods

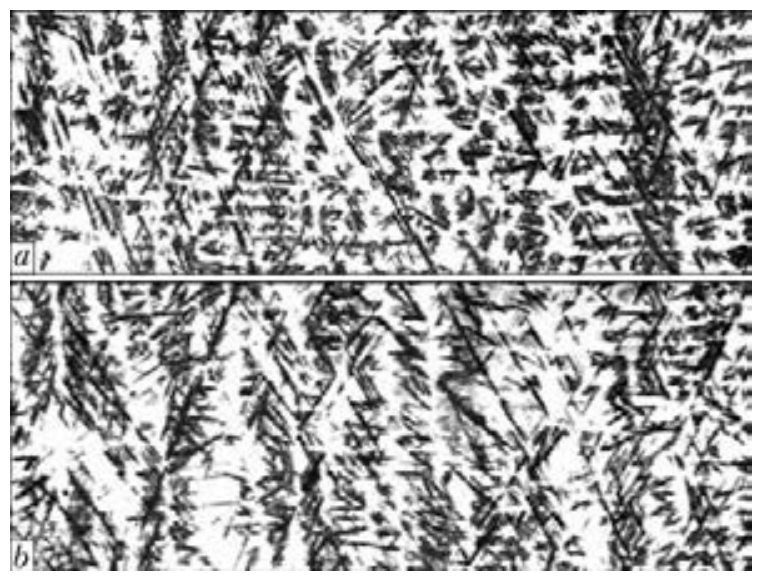

Figure 1. Microstructure $(\times 400)$ of metal deposited using flux-cored wire PP-Op-1 at the center $(a)$ and at the upper edge $(b)$ of deposited layer for detection and determination of grain size» and GOST 1778-70 «Steel. Metallographic methods for determination of non-metallic inclusions». Digital imaging of microstructures was obtained by the camera «Olympus».

The structure of metal, deposited using PPOp-1 wire with charge of master alloy, at the center of deposited layer represents martensite with coarse and fine needles of different etching and residual austenite (Figure 1, $a$ ). The hardness of martensite is $H V 1-542-606$, and that of residual austenite $H V 1-442-525$. At the upper edge the amount of residual austenite is not much increased, the size of needles of martensite is somewhat reduced (Figure 1, b). The hardness of martensite is $H V 1-530-542$, and that of residual austenite $H V 1-464-498$. The hardness of structural components along the entire height of deposited layer differs slightly. The characteristic structure of cast metal is also preserved along the entire height of deposited layer.

The structure of metal deposited using PPOp-2 wire with charge of ferroalloys is approximately the same as in metal deposited using wire PP-Op-1. At the center of the deposited layer the structure is composed of martensite and residual austenite (Figure 2, $a$ ), the needles of martensite have a large size. The hardness of martensite is $H V 1-542-606$, that of austenite $H V 1-442-468$. At the upper edge of deposited layer the structure is finer (Figure $2, b$ ), the hardness of martensite is $H V 1-514-572$, that of austenite $H V 1-416-442$. Also in this case the hardness of structural components along the height of deposited layer differs slightly. It is

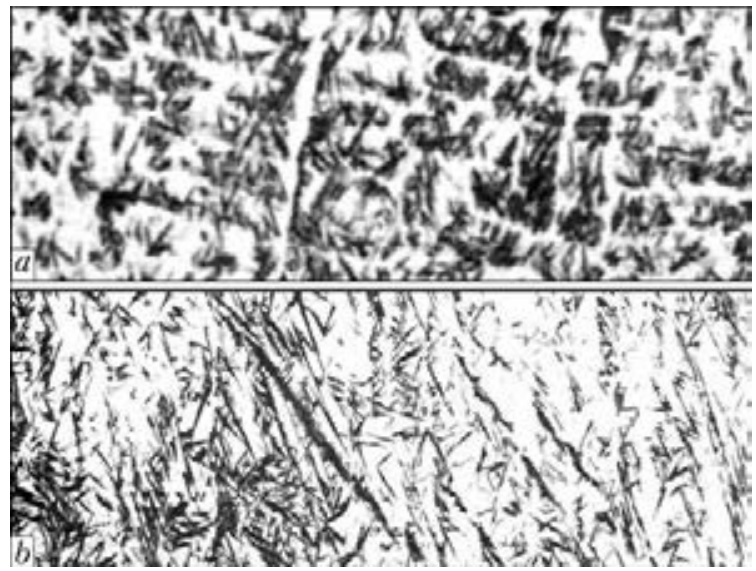

Figure 2. Microstructure $(\times 400)$ of metal deposited using flux-cored wire PP-Op-2 at the center $(a)$ and at the upper edge (b) of deposited layer 


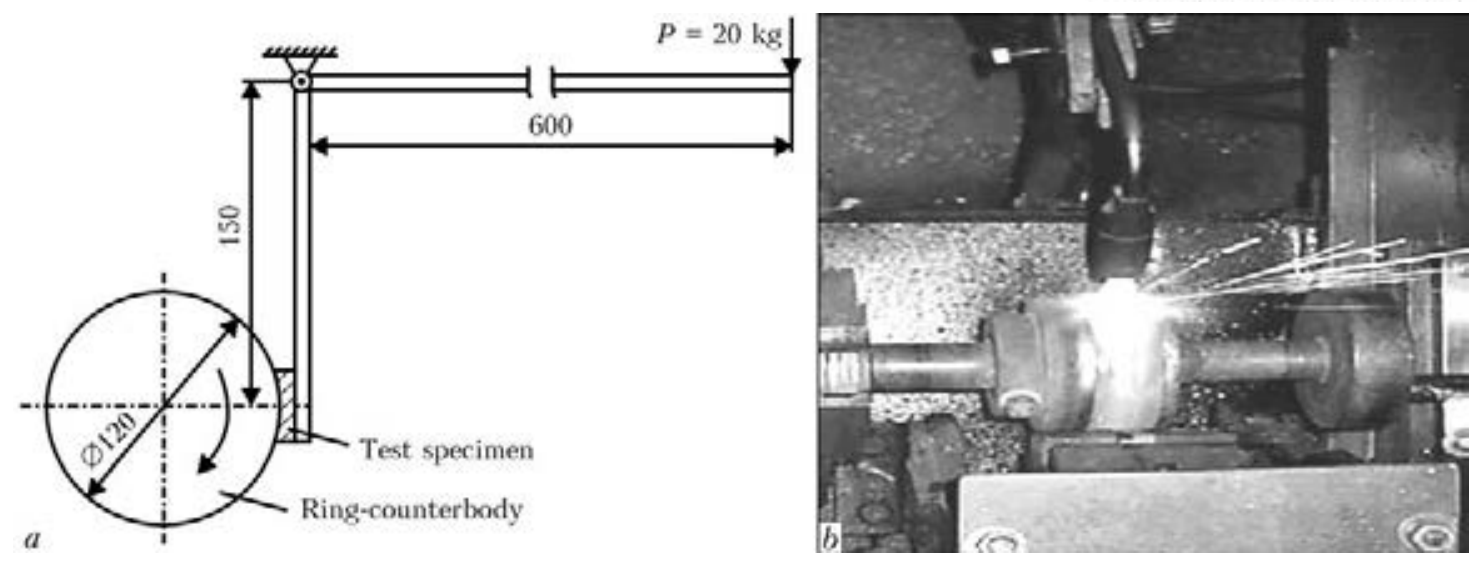

Figure 3. Principal scheme $(a)$, and process of testing wear resistance at metal-on-metal friction at elevated temperatures (b)

also close to the hardness of structural components of metal deposited using PP-Op-1 wire.

In both types of deposited specimens the pores in the lower layer of deposited metal were detected. At the same time in the specimen deposited using wire PP-Op-2 there is more pores and they are larger. The same concerns non-metallic inclusions, the number and size of which were studied on the polished non-etched specimens. In the investigated specimens the sulfides and oxysulfides, oxides and slag inclusions of finer sizes were detected. A number of non-metallic inclusions is higher in the specimen deposited using wire PP-Op-2. Obviously, the use of master alloy as a charge produced using electroslag remelting, allows decreasing the amount of non-metallic inclusions in the deposited metal.

The wear resistance of both types of deposited metal was investigated at a dry friction of metal on metal according to the scheme «shaft (ring)plane» at the high temperatures (Figure 3 ). The tests were carried out in the installation for complex investigations of properties of deposited metal [4]. The ratio of shoulders of lever mechanism with load of $20 \mathrm{~kg}$ (Figure 3, a) provides pressing of specimen to the abrasive ring with force equal to $800 \mathrm{~N}$.

The specific pressure in this case is approximately $100 \mathrm{MPa}$, that corresponds to the pressure which is undergone by the tool for hot deformation under industrial conditions. The heating of ring abrading the specimen is performed using a gas cutter. The temperature at the surface of specimen in the contact zone is about $650{ }^{\circ} \mathrm{C}$.

To carry out tests using pilot wires $\mathrm{PP}-\mathrm{Op}-01$ and $\mathrm{PP}-\mathrm{Op}-02$ in five or six layers the templates were deposited, of which the specimens with dimensions of $40 \times 10 \times 17 \mathrm{~mm}$ were manufactured. The thickness of deposited layer after machining was $8-10 \mathrm{~mm}$.
Table 3. Wear resistance of deposited specimens and counterbodies contacting with them at metal-on-metal friction at high temperatures

\begin{tabular}{||c|c|c||}
\hline \multirow{2}{*}{ Flux-cored wire } & \multicolumn{2}{|c|}{ Loss of mass, $\mathrm{g} / \mathrm{km}$} \\
\cline { 2 - 3 } & Deposited specimen & Counterbody of steel 45 \\
\hline PP-Op-01 & 0.0454 & 2.3905 \\
\hline PP-Op-02 & 0.0509 & 2.5064 \\
\hline
\end{tabular}

The tests on wear in friction of metal on metal at the elevated temperatures were carried out under the following conditions: load $800 \mathrm{~N}$; speed of rotation of ring-counterbody $30 \mathrm{rpm}$; oscillation amplitude of the specimen in vertical plane $20 \mathrm{~mm}$, oscillation frequency $62 \mathrm{~min}^{-1}$; temperature of specimen in the zone of abrasion $600-650{ }^{\circ} \mathrm{C}$; testing time was $1 \mathrm{~h}$. As a counterbody the rings of hardened steel 45 of $120 \mathrm{~mm}$ diameter were used. The test results (average values on three tested specimens) are given in Table 3.

As is seen from the data in Table 3, the wear resistance of specimens, deposited using pilot flux-cored wires and that of the bodies contacting with them, is at the same level. Thus, the master alloy produced by utilization of grinding wastes production can be successfully used as a charge in surfacing flux-cored wires.

1. Kiparisov, S.S., Padalko, O.V. (1993) Resource-saving and natural potential of powder materials and technologies: Realization in the field of secondary resource processing. Poroshk. Metallurgiya, 6, 1-4.

2. Gabrielov, I.P., Kerzhentseva, L.F. (1985) Properties of powder made from metal-abrasive waste of highspeed steel. Ibid., 9, 133-136.

3. Lentyugov, I.P., Ryabtsev, I.A., Kuzmenko, O.G. et al. (2008)' Metal-abrasive grinding wastes, methods of their processing and experience of application in surfacing materials. The Paton Welding J., 9, 34-38.

4. Ryabtsev, I.I., Chernyak, Ya.P., Osin, V.V. (2004) Block-modular unit for testing of deposited metal. Svarshchik, 1, 18-20. 